\section{Commentary: No pain no gain- what is the best retraining pathway for patients with corrected transposition?}

\author{
Jonathan M. Chen, MD
}

Since Yacoub's first description of pulmonary artery (PA) banding to (re-)train the systemic left ventricle (LV)—and Mee's extension nearly a decade later to patients with corrected transposition (ccTGA) - surgeons have struggled to elucidate the best determinants of "switchability" for the untrained $\mathrm{LV}^{2,3}$ Some have advocated for a loose band $(50 \%$ of systemic pressure) to allow for growth and potentially limit edema/fibrosis, others to "band until you can band no more," targeting values closer to $75 \%$ to $90 \%$ of systemic pressure with or without an additional volume load. ${ }^{4,5}$ Yet, although the traditional use of LV mass as a surrogate of operability is intuitively attractive, there remains some unpredictability as to which retrained ventricles are at risk for late failure. ${ }^{6}$ In this issue of the Journal, Mainwaring and colleagues ${ }^{7}$ report an observed relationship between LV mass and pressure that suggests a distinction between "normal" and "pathologic" hypertrophy during retraining. While they did not demonstrate the accuracy of such mass and volume "fractions" to predict later success or failure with the double switch, their data indicate that some $(10 \%)$ patients will exhibit exaggerated hypertrophy in response to pressure load, implying fundamental myocardial abnormalities that could preclude later anatomic repair.

As congenital surgeons are keenly aware, perfect calibration of a PA band intraoperatively is a misnomer; variability in physiologic baseline, pulmonary vascular resistance, and depth of anesthesia all can conspire against exacting placement and thus the process often conforms to a Goldilocks

\footnotetext{
From Cardiothoracic Surgery, Children's Hospital of Philadelphia, Philadelphia, Pa. Disclosures: Author has nothing to disclose with regard to commercial support.

Received for publication Oct 25, 2019; revisions received Oct 25, 2019; accepted for publication Oct 25, 2019; available ahead of print Dec 12, 2019.

Address for reprints: Jonathan M. Chen, MD, Cardiothoracic Surgery, Children's Hospital of Philadelphia, 3401 Civic Center Blvd, Suite 8574, Philadelphia, PA 19104 (E-mail: chenj14@email.chop.edu).

J Thorac Cardiovasc Surg 2020;159:2367-8

0022-5223/ $\$ 36.00$

Copyright () 2019 by The American Association for Thoracic Surgery

https://doi.org/10.1016/j.jtcvs.2019.10.168
}

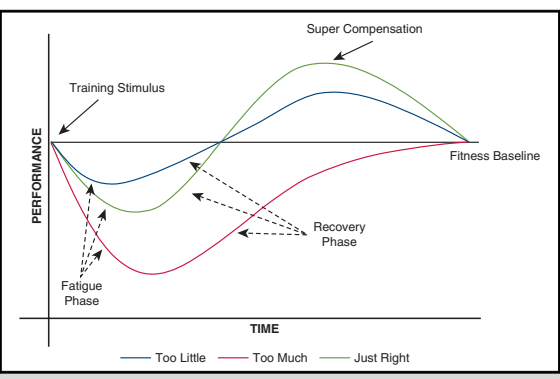

The Goldilocks Principle, reflecting postulates of exercise recovery (here for long-distance running).

\section{CENTRAL MESSAGE \\ Better characterization of the relationship between changes in LV mass and pressure for pa- tients with corrected transposi- tion who undergo pulmonary artery banding may help deter- mine optimal candidacy for double-switch procedure.}

paradox: inevitably, the band is either too tight or too loose. Unsurprising, only half of the cohort escaped with only one PA band procedure (12 had two, 3 had three). Interestingly, even for those who followed a "predictable" retraining pathway with regard to LV pressure accrual, their gain in LV mass was less than would be seen for patients who did not require retraining, and indeed those who began with greater LV/right ventricular pressure ratios and LV mass more often achieved successful retraining.

Yet, these data were observational and were not used to determine candidacy for double switch. ${ }^{6}$ Still unclear is (1) the relationship of age and tricuspid valve anatomy to the training process and (2) what threshold values for LV mass best reflect "optimal" training. ${ }^{8}$ The Goldilocks principle would submit that some amount of PA banding may be "just right" for those with ccTGA; the question remains how to avoid over- or undershooting the target, and how to identify those for whom banding may represent ideal long-term palliation or, as important, those for whom (re) training will be futile (and potentially harmful). Had Goldilocks only a porridge thermometer - or better predictive parameters of chair strain and bed comfort-she might have avoided her drive toward empiricism. ${ }^{9,10}$ Similarly, we must applaud the authors for their pursuit of more accurate predictors of the "just right" pressure/mass/candidates for 
double switch. Mass and volume fractions may themselves simply represent surrogates that aid in discriminating among the heterogeneous anatomic substrates that constitute ccTGA for whom any further characterization and refinement in this domain is welcome.

\section{References}

1. Strength running. Goldilocks principle. Available at: https://strengthrunning com/2013/02/the-goldilocks-principle/goldilocks-principle-640x480/. Accessed October 23, 2019.

2. Yacoub MH, Radley-Smith R, Maclaurin R. Two stage operation for anatomical correction of transposition of the great arteries with intact ventricular septum. Lancet. 1977;1:1275-8.

3. Mee RB. Severe right ventricular failure after Mustard or Senning operation. Two-stage repair: pulmonary artery banding and switch. J Thorac Cardiovasc Surg. 1986;92:385-90.

4. Ohye RG, Si M, Bove EL, Hirsch-Roman JC. Left ventricular retraining: theory and practice. Semin Thorac Cardiovasc Surg Pediatr Card Surg Ann. 2015;18:40-2.
5. Zartner PA, Schneider MB, Asfour B, Hraska V. Enhanced left ventricular training in corrected transposition of the great arteries by increasing the preload. Eur J Cardiothorac Surg. 2016;49:1571-6.

6. Quinn DW, McGuirk SP, Metha C, Nightengale P, deGiovanni JV, Dhillon R, et al. The morphologic left ventricle that requires training by means of pulmonary artery banding before the double-switch procedure for congenitally corrected transposition of the great arteries is at risk of late dysfunction. J Thorac Cardiovasc Surg. 2008;135:1137-44.

7. Mainwaring RD, Patrick WL, Arnuamata A, Chan F, Newman B, Rosenblatt BA, et al. Left ventricular re-training in corrected transposition: relationship between pressure and mass. J Thorac Cardiovasc Surg. 2020; 159:2356-66.

8. Myers PO, del Nido PJ, Geva T, Bautista-Hernandez V, Chen P, Mayer JE, et al. Impact of age and duration of banding on left ventricular preparation before anatomic repair for congenitally corrected transposition of the great arteries. Ann Thorac Surg. 2013;96:603-10.

9. Pearson EJ. Comfort and its measurement—a literature review. Disabil Rehabil Assist Technol. 2009;4:301-10.

10. Buckle P, Fernandes A. Mattress evaluation-assessment of contact pressure, comfort and discomfort. Appl Ergon. 1998;29:35-9. 